\title{
BIG DATA TECHNOLOGY IN ESTABLISHMENT AND AMENDMENT OF WATER MANAGEMENT STANDARD
}

\author{
BAI, Y. ${ }^{1,2}-$ BAI, X. ${ }^{1 *}-$ LIN, L. ${ }^{1}-$ HUANG, J. ${ }^{1}-$ FANG, H. W. ${ }^{2}-$ CAI, K. ${ }^{1}$ \\ ${ }^{1}$ Resource and Environment Branch, China National Institute of Standardization, Beijing \\ 100191, China \\ ${ }^{2}$ Department of Water Conservancy, Tsinghua University, Beijing 100084, China \\ *Corresponding author \\ e-mail: baixue@cnis.gov.cn \\ (Received 24 $4^{\text {th }}$ Oct 2016; accepted 20 $0^{\text {th }}$ Dec 2016)
}

\begin{abstract}
Based on the artificial intelligence and the big data analysis, the big data technique is a basic procedure combining the composition, consultation, release, implementation and supervision of the standard when it is applied in the development and revision of water management standards, aiming to solve difficulties encountered in the standard implementation supervision and mobilizing enterprises. The application is referred to as "standards of intelligent water management". "Intelligent standards of water management" not only motivates enterprises to participate more but also promotes technological innovations of water management as well as the reform-upgrade of water application so that these standards adopted from people can finally benefit people. Based on the whole life cycle process of the standard development, the paper constructs the integrated solution of intelligent water management standards from three angles including basic data resource platform, unified data platform and data resource utilization, and describes the integration framework of the solution from three levels including data integration specifications, portal integration application construction and data integration application construction. The paper thoroughly analyzes the feasibility and value of intelligent water management standards.
\end{abstract}

Keywords: water resource management; saving standard; big data method; data platform; water resources

\section{Introduction}

China is deficient in water resources with the water resource quantity per capita at approximately $2,100 \mathrm{~m}^{3}$, only accounting for $28 \%$ of the world water resource quantity per capita. Water resources have gradually become scarce resources that influence China's social and economic development. Moreover, the management and study of water resources are greatly affected by the loss of basic data for water resources. To realize the sustainable development of water resources, the utilization efficiency of water resources should not only be increased by traditional means such as exploiting new water resources and saving water available and the management style and theory of water resource application should also be innovated and improved. Relevant standards of water management are used to realize the reasonable distribution and utilization of water management by managing water resources fundamentally. The big data technique can be further adopted to establish the corresponding basic data investigation and reorganization database, facilitating the development and revision of water standards. It not only increases the basic data of Chinese water resources but also breaks the limits of the current water management standard setting, improving the basic data of water and relevant standard setting (Liu, 2010). 
Relatively mature systems of water management standards have been established abroad. Overseas, watershed management more relies on laws and regulations for watershed protection, such as Law of Water and Soil Conservation enacted in America, River Law promulgated in Japan and National Water Law enacted in Austria. The Australian government has made it mandatory to implement the scheme of Water Efficiency Labeling and Standard (WELS) nationwide. In the WELS scheme, it is stipulated that the minimum water efficiency standard should be applied in domestic water products nationwide (Xiao et al., 2000). Singapore started to initiate the Water Efficiency Labeling Scheme, which is called "WELS" for short in 2006 (Voluntary \& Mandatory). American Environmental Protection Agency (EPA) launched a WaterSense voluntary certification program which is intended to popularize water conservation products. Modes of both Chinese energy efficiency standard and Australian water efficiency standard are referred to in the content structure of Chinese water efficiency standard as well as innovative and competitive designs are allowed, but no specific requirements are made on technical specifications or design details of products and only water-use efficiency performances are stipulated ( $\mathrm{Ni}, 2010)$. In addition, standards of water resource management are constructed in terms of a certain stage or full stage of the life cycle by referring to the following standards including water footprint evaluation criterion study (Shao, 2008), recycle design (ISO 14046-2014) and disassembly design (Santini et al., 2010) in green designs of water-use products as well as full life cycle evaluation (Sanchoy et al., 2000) and energy conservation design (Guinee et al., 2001) of water-use products.

Theories and methods of big data have been applied in multiple fields of water resource management such as sewage treatment, circulating water use and unconventional water resource management etc. The water-oriented big data analysis model mainly includes SVM (Support Vector Machine) LEAP model (Long Range Energy Alternatives Planning System) and WEAP (Water Evaluation and Planning System) (Cao et al., 2010). Zeng and Qi conducted the analysis of sewage management by using SVM model (Zeng et al., 2006, Qi et al., 2008). Wang used LEAP model to construct the $\mathrm{CO}_{2}$ emission picture of Chinese iron and steel industry from 2000 to 2030 (Wang et al., 2006). Chang used LEAP model to construct LEAP-Shanghai model (Chang and Pan, 2014). With Xiamen City as a research case, Cao used LEAP model to analyze the situations of energy conservation and emission reduction and evaluated the corresponding potential of Xiamen through quantitative analysis (Cao et al., 2010). WEAP model has been widely applied in the evaluation of future water resource supply-demand balance in watersheds as well as the scenario analysis of climate-driven or decision-driven water resource management by departments concerned of various countries in the world (Hu et al., 2009).

The big data method is used for developing and revising relevant standards of water management by establishing the basic database of Chinese water resources in the paper. The paper mainly has the following innovations: (1) the big date method is first applied in the development of water management standards, breaking the traditional standard establishment and enriching means for water management standard establishment; (2) the big data platform of water resource management is constructed by establishing the basic data-warehousing of Chinese water resources and systematically reorganizing the environmental data of typical watersheds.

The paper consists of four parts: the first part mainly introduces the development status and meaning of relevant water management standards based on big data (Ding and Perella, 2016); the second part covers the procedures of intelligent water management standards; the third part describes the construction of big data platform; the final part is the conclusion of the paper. 


\section{Meaning of intelligent water management standards based on big data}

\section{Intelligent water management standards}

Based on the artificial intelligence and the big data analysis, "the standard of intelligent water management" is a basic procedure combining the composition, consultation, release, implementation and supervision of the standard, aiming to solve difficulties encountered in the standard implementation supervision and mobilizing enterprises. "Intelligent standards of water management" not only motivate enterprises to participate more but also promotes the reform-upgrade of quality testing procedures so that these standards adopted from people can finally benefit people.

The generation procedure of "intelligent water management standards": In drafting relevant water management standards, only large leading enterprises are selected in terms of their comprehensive strength, product quality, technology and innovations with opinions from medium and small-sized enterprises almost excluded. However, regarding these medium and small-sized enterprises, their opinions of product quality and content best reflect the thinking of standard followers, assisting the establishment of standards. "Intelligent water management standards" mean collecting, cleaning and analyzing enterprises' opinions on the internet through using the data collection technology. Subsequently, the investigation data of enterprises are depended on to provide objective truth and reflect the quality, a major concern of enterprises, in setting standards.

The consultation of "intelligent water management standards": In the existing standard consultation, standards are mainly released on the internet or the industry association is entrusted for consultation, but the timely feedback always fails. When "intelligent water management standards" are used for consultation, opinions can be precisely released to standard users by using the big data enterprise image technology. Moreover, the progress of opinions can be given feedback according to the release time and the real-time dynamics of the contact person, and then these opinions are collected and submitted to solicitors by adopting the cluster algorithm. In "intelligent water management standards", opinions are sought actively rather than passively, shifting the consultation mode from supply-oriented to demand-oriented, so that the relevant quality content, a major concern of enterprises, can be reflected in standards.

Release, implementation and supervision of "intelligent water management standards": In "intelligent water management standards", the intelligent sensing technology is adopted to realize real-time monitoring---whether enterprises execute these standards in strict accordance with standards in the production. In the circulation link of products, the public is guided to obtain relevant information of standards by guiding them to use the query website of standards or APP. In this way, the scanning of two-dimension code enables people to know the specific standard implementation of the product in the production so that they can monitor whether the products that they use accord with standards. The supervision of "intelligent standards" integrates the standard and the product quality.

\section{Foundation datasets of water resources}

The total volume of water resources is 2.8142 trillion $\mathrm{m}^{3}$ in China with the annual runoff volume reaching 2.7 trillion $\mathrm{m}^{3}$. Problems involved in the management of Chinese water resource data mainly come from the following four aspects: (1) the large volume of basic water resource data covers a wide range; (2) heterogeneity is available in the data distribution of water resources; (3) there are difficulties in mutually sharing the basic data of water resources; (4) the statistical data require the diversity. 
Given the current situation that the basic data of Chinese water resources are urgently required in the benchmark study, typical waters are first selected as research regions in constructing the foundation database of water resources including Taihu Lake, Chaohu Lake, Dian Lake, Liao River, Songhua River, Yangtze River, Yellow River and Pearl River to systematically construct the water resource benchmark and foundation data warehouse. Specifically, the construction includes basic data concerning water volume, hydrobiological species, physical and chemical parameters for basic waters, typical pollutant content distribution as well as aquatic ecotoxicology of typical pollutants etc. General methods are formed to deal with various data analysis and data processing by systematically analyzing key links that influence the data quality and improving scientific means of data quality, and basic data of Chinese water resources are established including water volume, aquatic organisms, physical and chemical parameters, pollutant content as well as ecotoxicology. Subsequently, the corresponding datasets are constructed: the foundation dataset of aquatic organisms in typical Chinese waters, the dataset of basic physical and chemical parameters in typical Chinese watersheds and waters, the dataset of typical Chinese pollutant content distribution in main waters as well as that of aquatic ecotoxicology for typical Chinese pollutants. In this way, a system of complete and standard foundational data, datasets and map sets are formed, which can be referred to in setting Chinese water resource standards, by constructing these datasets of basic water resources.

\section{Technological implementation of intelligent water management standards}

\section{Overall structure of intelligent water management standards}

To ensure that intelligent water management standards can become a unified whole in the process of production, consultation, implementation and release and that the complete precise data decision support information can be obtained in the standard setting as well as improve the information sharing of the standard setting, the unified data information platform of standard setting should be designed from the top level to support the unified storage and management of relevant data resources in the standard setting. Various data resources of the standard setting can be mutually shared on the platform.

The unified data platform of intelligent water management standards is shown in Figure 1. Based on establishing the unified information coding system with standards, the technical framework of data resources is divided into three levels of framework in intelligent water management standards: basic data resource platform, unified data platform and data resource utilization.

\section{Basic data resource platform}

With the water management standard setting as the core, the platform organizes the deploying of basic data resources. The data, which are established by water management standards, are stored in the backend database of all business systems according to business categorization to support the normal stable operation of the business system. For example, the setting requirements of both the industry and enterprises are included in the business system produced by water management standards. The consultation data includes opinions from ministries and commissions, enterprises and the internet etc. 


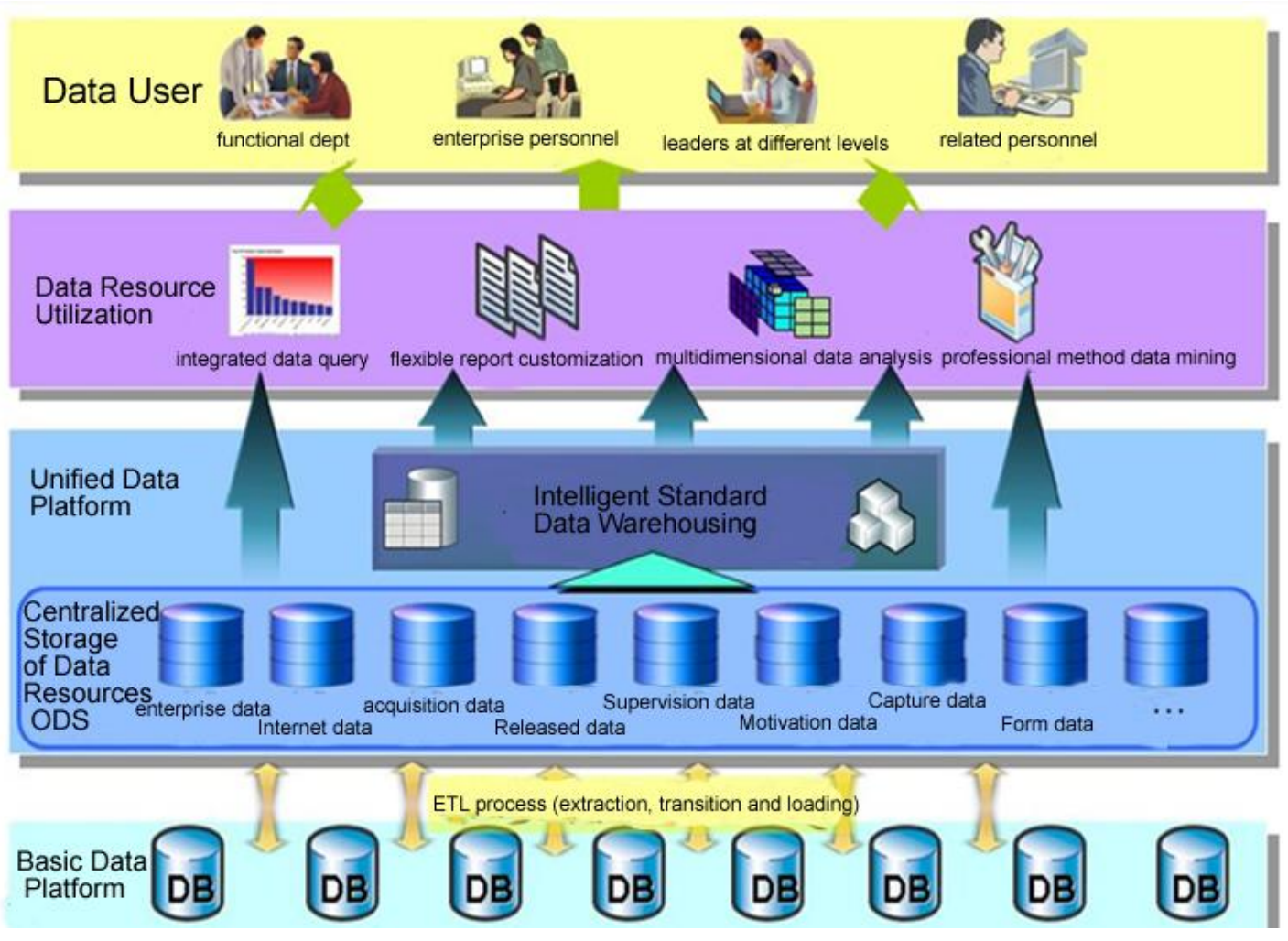

Figure 1. Technical framework of information resources

\section{Unified data platform}

The unified data platform is the "administrator" (internal) as well as the "supplier" (external) of intelligent water management data. Internally, various centralized business data resources are managed in a unified way to realize "classified storage and centralized management" after the formulation of whole water management standards. Externally, the unified data platform also serves as open data resources for the standard formulation, allowing leaders at different levels and business personnel to visit intelligent standard data information through authorization control and also laying foundations for the mutual sharing of various business data.

The unified data platform consists of two parts: consolidated data storage and data warehousing of intelligent water management standards.

With the business data category as the core, the consolidated data storage organizes the deploying of consolidated data resources. In the data concentration, ETL tools are used (including datastage and powermart etc.) to extract, transform and load the business data such as standard draft data and standard consultation data to the intelligent and standard ODS (Operational Data Store) so that the consolidated storage and unified management can be realized according to the business category.

Meanwhile, the consolidated data storage also provides necessary business sharing information for various systems so that businesses can obtain the required data from ODS and the smooth execution of the business can be guaranteed. For example, the information of the internet and enterprises can be obtained regularly in lots from ODS to complete businesses including the investigation data collection of standard approvals as well as the market condition analysis of relevant industries and enterprises etc in standard approval plans. 
With business subjects as the core, the data warehousing of intelligent water management standards is based on the consolidated storage of intelligent standard data (namely ODS data) and organizes the data deploying of aggregation model (Fact and Dimension Data). Moreover, various business subjects and relevant data lay the data foundations for the deep-level utilization of multidimensional data analysis and integrated data query in the standard scope of consolidated storage for data warehousing.

\section{Data resource utilization}

Based on the consolidated data storage (ODS data) and the standard data warehousing of intelligent water management standards, it provides multidimensional data analysis for business activity supervision including assisting business decisions and project approvals etc. In analyzing the setting of some really professional standards, the professional algorithm is required for deep data mining according to specific business needs of relevant enterprises. The data resource utilization transforms the ordinary business data on the unified data platform into "knowledge" beneficial to the standard setting. Meanwhile, functional departments, business divisions and business personnel that set the standard can make the integrated data query on the platform and obtain the business data in the uniform format for the standard setting. For example, enterprise personnel can check the accuracy of the information provided by enterprises as well as the relationship between relevant standard information and enterprises in the standard setting process, standard setting personnel can focus on the data of the standard setting process real time and dynamically, and decision makers can pay attention to the standard implementation and evaluation data on the internet etc. In this way, enterprises, standard setting personnel and decision makers can mutually coordinate and participate in the full life cycle of the standard setting together.

\section{Overall integrated structure of intelligent standard application system}

The preliminary analysis is made based on the current situation of the standard setting and information development trends that the integrated application of "one set of standards and three levels" can be established in the integration scheme of big data analysis system for intelligent water management standards. They are data integration standard, data integration, business integration and interface integration respectively. The overall structure of the integrated system scheme is shown in Figure 2.

\section{Data integration standard}

The data integration standards should be established to guarantee the smooth construction of the intelligent standard system integration platform as well as to lay solid foundations for the future information system development, inter-system data interaction and integrated operation and maintenance management. For example, these standards include data interface specification, basic encoding specification, specification of integration environment operation and maintenance as well as information system development specification, data application chart is shown in Figure 3. 


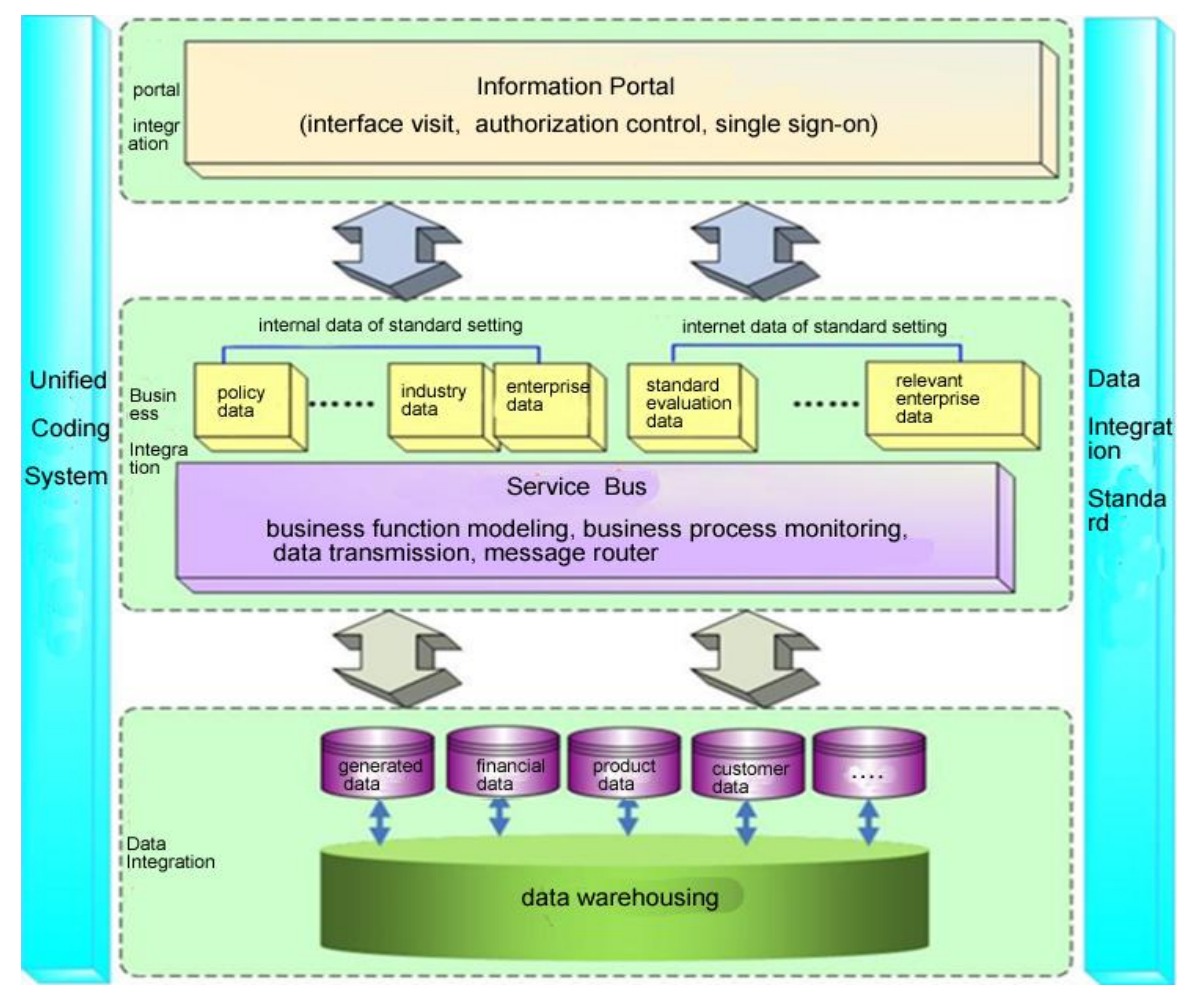

Figure 2. Application Integration Structure

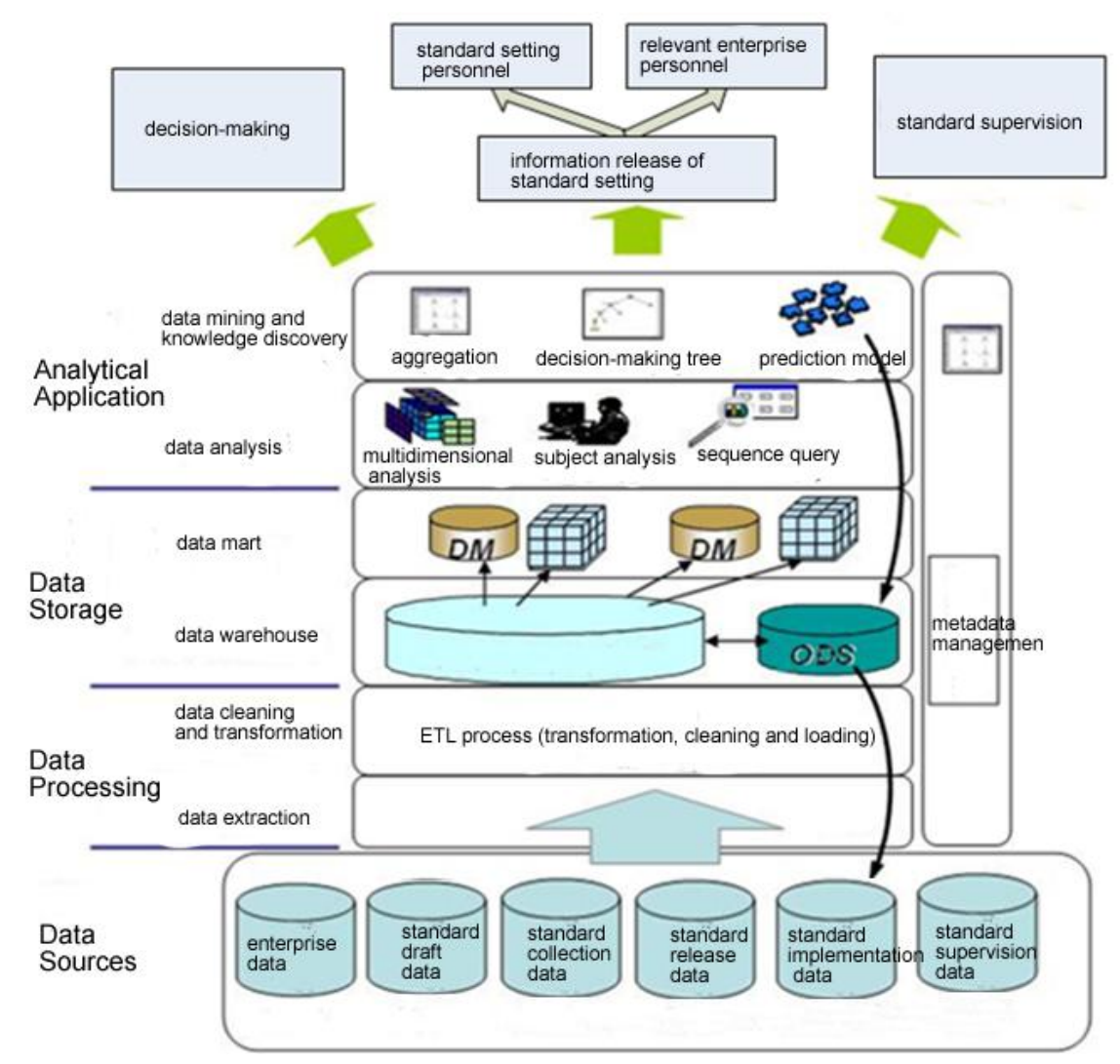

Figure 3. Data application chart

APPLIED ECOLOGY AND ENVIRONMENTAL RESEARCH 15(3):263-272. http://www.aloki.hu • ISSN 15891623 (Print) • ISSN 17850037 (Online) DOI: http://dx.doi.org/10.15666/aeer/1503_263272 (c) 2017, ALÖKI Kft., Budapest, Hungary 


\section{Portal integration application construction}

The portlet integration technology is used to establish the information portal system of intelligent standards, integrating the interfaces of main application systems including the generation, consultation and implementation of standards and realizing the consolidated information display of multiple application systems. In the portal integration design, "three-concentration" concepts should be reflected: namely login certification concentration, information display concentration and functional operation concentration. Meanwhile, the single sign-on technology (SSO) and concentrated authentication management are used to make the information portal system become the only "gate" of the application system, really realizing functions of "unified authentication, concentrated visit, unified interface style and concentrated functional operation".

Various Portlet containers provided by the Portal middleware are used to make interface encapsulation of business systems including the standard draft setting, the standard consultation and the standard release etc, and interfaces of different systems are inserted to the unified portal platform, laid out and displayed in accordance with individualization demands. The user can visit the portal platform through single sign-on (one authentication in multiple systems) and make concentrated operation of relevant systems within the stipulated authority after the authentication passes.

\section{Data integration application construction}

With the intelligent standard data warehousing as the support of data analysis and data decision-making, multiple standard datasets are formed in terms of different analysis subjects to conduct the business analysis and data statistics, finally transforming the analysis results into "knowledge" beneficial to the establishment of intelligent standards. The knowledge facilitates the business activity analysis for departments of economic operation and management as well as helps relevant leaders to make decisions.

\section{Conclusions}

The establishment of big-data water resource management standards can collect and organize the basic data of water resources and assists the setting of water resource management standards in the paper, but still a lot of problems remain to be solved. These problems include (1) Water resource data standardization: the collected data sources include automatic collection data of watersheds, reported data of government agencies, reported data of enterprises and acquired internet data from multiple organizations and channels. As participants report the data in different formats and styles, problems available in the standardization and unification of data formats pose difficulties to data integration and data cleaning. (2) Supervision problems in implementing relevant water management standards: The big data technique is used to realize the basic database of water resources and assist the setting of relevant standards, but enterprises or individuals fail to collect the real-time supervision data in following these standards, posing some problems to the implementation supervision analysis of relevant water management standards

The applied implementation of "intelligent water management standards" not only solves the problems of basic data loss in China but also helps to establish relevant water management standards through basic data, making it easier for enterprises to participate in the standard setting. The establishment of relevant water management standards aims 
to solve problems facing water resources in the long run. With the big data analysis as the tool, the corresponding water management standards are set and implemented to save water as well as to reasonably plan the development and distribution of water resources.

Acknowledgements. The paper is funded by National Natural Science Foundation Programs of China (NSFC) (71271012) as well as key and special project of MWR (Chinese Ministry of Water Resources) (2016YFC0403004).

\section{REFERENCES}

[1] Cao, B., Lin, J. Y., Cui, S. H., Tang, L. N. (2010): Scenario analysis on LEAP-oriented energy conservation and greenhouse gas emission reduction potentials in Xiamen. Chinese Journal of Ecology 30(12): 3358-3367.

[2] Chang, Z., Pan, K. X. (2014): Analysis on LEAP-oriented long-term energy consumption and carbon emission in Shanghai. - Contemporary Economy 350: 98-106.

[3] Ding, G., Perrella, M. (2016): Study of Chinese Continental Crustal thickness based on the data of EGM2008. - Journal of Mechanical Engineering Research and Developments 39(2): 478-482.

[4] Guinee, J. B., Huppes, G., Heijungs, R. (2001): Developing an LCA guide for decision support. - Environmental Management and Health 12(3): 301- 311.

[5] Hu, L. T., Wang Z. J. (2009): Application of improved WEAP model in water resource management. - Journal of Hydraulic Engineering 40(2): 173-179.

[6] ISO 14046-2014. - Environmental management-Water footprint-Principles, requirements and guidelines.

[7] Li, Y., Li, H. P. (2010): WEAP-oriented water quality safety support scheme in Xitiaoxi watershed. - Advances in Water Science 21(5): 666-673.

[8] Liu, Z. L. (2010): Should sustainable consumption and production be a policy priority for developing countries and if so, what areas should they focus on?. - Natural Resources Forum, 34(1): 85-85.

[9] Ni, Y. Z. (2010): Study on water conservation management systems in Singapore and Australia. - Economic Development Mode Transformation and Self-Innovation-12th annual meeting of CAST (Volume I), Fuzhou, Fujian Province, China.

[10] Qi, Y. H., Wang, S. W., Liu, Z. F., et al. (2008): Combinational design of product structural elements for energy optimization. - Chinese Journal of Mechanical Engineering 44(1): 161-167.

[11] Sanchoy, K. D., Pradeep, Y., Raj, N. (2000): An approach for estimating the end-of-life product disassembly effort and cost. - International Journal of Production Research 38(3): 657-673.

[12] Santini, A., Herrmann, C., Passarini, F., et al. (2010): Assessment of ecodesign potential in reaching new recycling targets. - Resources Conservation and Recycling 54: 1128-1134.

[13] Shao, Q. Y. (2008): Water-saving product certification and implications in America. Europe and Australia. Energy Conservation and Environmental Protection 11, 16-19.

[14] Wang, K., Wang, C., Lv, Xue., et al. (2006): Analysis on LEAP-oriented CO2 emission reduction potentials in Chinese iron and steel industry. - Journal of Tsinghua University (Science and Technology) 46(12): 1982-1986. 
[15] Xiao, B., Gao, J. R., Liu, G. Q., Ding, X. L. (2000): Watershed Management in Foreign Countries. - Journal of Northweast Forestry University 15(3): 112-117.

[16] Zeng, G. M., Li, X. D., Jiang, R., et al. (2006): Fault Diagnosis of WWTP Based on Improved Support Vector Machine. - Environmental Engineering Science 23(6): 1004-1054. 